DE DE GRUYTER

OPEN

\title{
ENDOMETRIAL CYTOLOGY AT LUTEAL AND FOLLICULAR PHASES OF THE OVARIAN CYCLE IN COWS*
}

\author{
Piotr Brodzki ${ }^{1}$, Adam Brodzki², Łukasz Kurek ${ }^{3}$, Jan Marczuk $^{3}$, Marcin R. Tatara $^{4}$ \\ ${ }^{1}$ Department and Clinic of Reproduction, \\ ${ }^{2}$ Department and Clinic of Animal Surgery, \\ ${ }^{3}$ Department and Clinic of Internal Medicine, Faculty of Veterinary Medicine, \\ University of Life Sciences in Lublin, Głęboka 30, 20-612 Lublin, Poland \\ ${ }^{4}$ Department of Animal Physiology, Faculty of Veterinary Medicine, \\ University of Life Sciences in Lublin, Akademicka 12, 20-950 Lublin, Poland \\ Corresponding author: wetdoc@interia.pl
}

\begin{abstract}
The aim of the study was to examine cytological changes in the uterus in cows during the follicular and luteal phases of the ovarian cycle, as well as to compare two different methods (brush and flushing) used for cytological material collection and to evaluate their usefulness for monitoring of the endometrium. Ovarian cycle phases were confirmed by ultrasound and by the level of sex hormones (17- $\beta$-estradiol and progesterone). The following types of cells were identified in the cytological smears: type I - surface cells; type II - intermediate cells; type III - basal cells; polymorphonuclear leukocytes (PMNs); L - lymphocytes. The number of type I and III cells was statistically significantly higher in the follicular phase than in the luteal phase, both in smears prepared using a brush $(\mathrm{P}<\mathbf{0 . 0 0 1})$ and by uterine flush $(\mathrm{P}=\mathbf{0 . 0 0 3})$. The number of type II cells was statistically significantly higher in the luteal phase than in the follicular phase in both methods $(\mathrm{P}<\mathbf{0 . 0 0 1})$. The results of the study show that phases of the ovarian cycle in cows can be identified based on changes in the quality and percentage of different types of endometrial cells in a cytological examination.
\end{abstract}

Key words: endometrial cytology, ovarian cycle, cows

Reproductive problems in dairy cows can result from numerous factors. Most causes of infertility are closely correlated, and result in an inability to become pregnant (Bisinotto et al., 2012; LeBlanc, 2012; Wathes, 2012). Of course, not all of the mechanisms and causes of infertility are known, despite many studies that have been conducted in this area of research. A healthy endometrium is a fundamental condition for the cow's fertility and ability to become pregnant. The state of the endometrium should be considered first in fertility disorders in dairy herds. New methods continually introduced into gynaecological practice make it possible to evaluate the state of

*Source of financing: WKP/DS-1. 
the endometrium (Kasimanickam et al., 2004; Sheldon et al., 2009; Chapwanya et al., 2010; Turner et al., 2012). One of these methods is cytological examination. Our observations indicate that endometrial cytology is not a commonly used method in the diagnosis of reproductive disorders in cattle, however in recent years interest in this type of diagnostic procedure has increased significantly. It is known that proper preparation and evaluation of cytological smears depends not only on the experience of those performing the test, but also on the selection of an appropriate method for obtaining material from the uterus. One of two well-known methods can be chosen: a brush cytology and a uterine flush (Kasimanickam et al., 2004; Garoussi et al., 2010; Prieto et al., 2012). According to literature data, a cytological examination is performed in cows mainly in order to rule out or confirm subclinical endometritis when changes cannot be seen in the uterus, or when changes are visible in ultrasonography. Cytological examination can also be very useful in monitoring the postpartum period in cows (Kasimanickam et al., 2004, 2005; Jeremejeva et al., 2010). It enables the earliest possible detection and treatment of cows with endometritis that has persisted for too long (Sheldon and Dobson, 2004; Sheldon et al., 2006; Jeremejeva et al., 2010). The cytological examination in such cases is restricted to calculating the percentage of cells characteristic for inflammatory infiltration in various ways, i.e. leukocytes, mainly segmented neutrophils and lymphocytes. There are various methods for counting these cells. According to some authors, 100 cells visible in the smear should be counted and the percentage of neutrophils should be calculated (Kasimanickam et al., 2004, 2005). Another method is to count 150 cells visible in the smear and determine the percentage of neutrophils among them, or to count the cells visible in 10 fields of view and determine the percentage of neutrophils (Melcher et al., 2014; Prieto et al., 2012). It seems interesting not only to evaluate the uterus in the case of inflammation, but also to compare the state of the endometrium in different phases of the oestrous cycle.

The aim of the study was to examine cytological changes in the uterus in cows during the follicular and luteal phases of the ovarian cycle and to determine differences in the cellular pattern in both periods, as well as to compare two different methods (brush and flushing) used for cytological material collection and evaluate their usefulness for monitoring the condition of the endometrium free of inflammatory changes.

\section{Material and methods}

The study was conducted on 20 Holstein-Friesian (HF) clinically healthy cows. The cows were kept in the same environmental conditions and were fed and housed (tie-stall system) in an identical manner. The cows were aged 3-6 years. Feeding was based on the TMR system and included maize silage, grass silage, hay, straw, grain meal, soy meal, and mineral and protein supplements. All of the experimental animals were 60-80 days after parturition. All of the cows received intramuscular injections of dinoprost (Dinolytic (C) Pfizer Manufacturing Belgium N.V., Puurs, Bel- 
gium), twice at an 11-day interval (25 milligrams), to induce luteal regression and oestrus. After signs of oestrus occurred following the 2 nd injection of dinoprost, endometrial samples were collected using either cytological brushes $(n=10)$ or uterine flush $(n=10)$. The procedure was repeated in all cows after 10 days in the luteal phase.

Apart from observing signs of oestrus, ultrasonographic examination using Honda HS 1500 apparatus (Honda Electronics Co., Ltd, Toyohashi, Japan) was performed to confirm the presence or absence of a follicle or a corpus luteum in the ovaries. The presence of a corpus luteum was confirmed by ultrasonography. If the cows did not display signs of oestrus following ovarian cycle synchronization, or ultrasonography did not confirm the presence of a follicle or corpus luteum, the cows (2) were eliminated from the experiment and replaced with cows that had responded as expected to the luteolytic dose of dinoprost. Endometrial cytology was performed using two methods - with a cytological brush - (B) (Jiangsu Yada Technology Group Co., Jiangsu, China) and by uterine flush - (F) Foley catheter (Jørgen Kruuse, Marslev, Denmark). The first method was carried out using an endometrial cytology brush, specially adapted for this purpose. The procedure for collecting material was the same for all the experimental animals. After the steel catheter (Jørgen Kruuse, Marslev, Denmark) was passed through the cervix to the base of the uterine horn, the brush was released from the tube and rotated around its long axis within the uterus to collect material for examination. The insertion of the catheter and collection of material from the uterus was controlled by hand through the rectum. After a few rotations the brush was retracted into the catheter and removed from the uterus. Cytological smears were made directly from the brushes as imprint specimens on microscope slides. The second method for collecting material involved using a uterine catheter with a syringe to infuse $50 \mathrm{ml}$ of $0.9 \%$ saline solution into the uterus. The uterus was massaged through the rectum for a few minutes, and then the saline solution was aspirated. As much fluid as possible was recovered, about $40 \mathrm{ml}$, while some remained in the uterus. The fluid was taken to the laboratory and centrifuged at 800 $\mathrm{rpm}$ for $5 \mathrm{~min}$. The fluid over the sediment was removed and microscope slides were prepared from the sediment (Kasimanickam et al., 2005). After the smears obtained from both methods dried completely, they were fixed and stained with Hemacolor rapid staining (Merck KGaA, Darmstadt, Germany). The dried samples were examined under an Olympus CX 41 microscope (Olympus Corporation, Tokyo, Japan) at 1000x magnification.

Cytological evaluation of the smears was based on the type and quality of cells determined: the presence of cytoplasm, the presence of cell nuclei alone, the size of the cell nuclei, the shape of the cells and the cell nuclei, and the presence of additional cells such as leukocytes or erythrocytes, or even mucus or other artefacts visible in the smear. Following an overall qualitative evaluation, the percentages of particular types of cells in the samples were calculated: superficial, intermediate, basal cells, neutrophils and lymphocytes.

In addition to the ultrasound diagnosis of the ovarian structures mentioned above, the serum levels of progesterone and $17 \beta$-estradiol were determined to confirm the associated hormonal activity. Blood was collected from all cows twice, first in the 
follicular phase and second time in the luteal phase of the ovarian cycle. For this purpose $9 \mathrm{ml}$ of blood was collected from the external cervical vein of the cows into standard tubes Vacutest (Vacutest Kima srl, Arzergrande (PD), Italy). The blood was centrifuged at $2500 \mathrm{rpm}$ for $10 \mathrm{~min}$, and the serum was stored at $-20^{\circ} \mathrm{C}$ until analysis. The level of the hormones was assessed by ELISA (Enzyme-Linked Immunosorbant Assay) using commercial kits for determining 17- $\beta$ estradiol and progesterone levels (VIDAS, Biomerieux, Marcy l'Etoile, France). The intra-assay coefficients of variation (CV) for the ELISA were 2-14\%. The serum level of the hormones 17- $\beta$-estradiol $(\mathrm{pg} / \mathrm{ml})$ and progesterone $(\mathrm{ng} / \mathrm{ml})$ was determined using a Benchmark Plus spectrophotometric microplate reader with Microplate Manager Software V.5.2.1 (Bio-Rad Laboratories Inc., Hercules, California, USA).

\section{Statistical analysis}

All values are presented as means \pm SEM. Statistical analysis was performed using Statistica software (version 9.0) and repeated measures analysis of variance (ANOVA). The Shapiro-Wilk test was used in order to confirm the normal distribution of the examined features. Bonferroni post-hoc test and Student t-test were used to compare differences between the investigated groups of cows or diagnostic methods. The differences between the mean values were considered as statistically significant at $\mathrm{P}<0.01$.

\section{Results}

The following types of cells were identified in the cytological smears: type I (TI) - round or oval cell nuclei alone (small - TIs and big - TIb nuclei), or endometrial cells with atrophic cytoplasm and round or oval nuclei, highly vacuolated and with signs of atrophy - superficial cells (Figures 1 and 2); type II (TII) - cylindrical, conical or comma-shaped nuclei alone, or cells with atrophic cytoplasm and nuclei of shape - intermediate cells (Figures 3 and 4); type III (TIII) - cells with distinct cytoplasm and large or small round nuclei - basal cells (Figure 1); PMN (polymorphonuclear cells) - neutrophils, L- lymphocytes and A - artefacts: mucus, part of the cells, precipitated dye (Figures 4 and 5). The number of type I cells was statistically significantly higher in the follicular phase than in the luteal phase of the oestrous cycle (Table 1), both in the smears prepared using $\mathrm{B}(\mathrm{P}<0.001)$ and by $\mathrm{F}(\mathrm{P}<0.001)$. The percentage of type II cells was statistically significantly higher in the luteal phase than in the follicular phase of the oestrous cycle, both in the smears prepared with B $(\mathrm{P}<0.001)$ and by $\mathrm{F}(\mathrm{P}<0.001)$. The number of type III cells was statistically significantly higher during the follicular phase than in the luteal phase of the oestrous cycle, in the smears prepared using $\mathrm{B}(\mathrm{P}<0.001)$ and from lavage $(\mathrm{P}=0.003)$. The number of PMNs was statistically significantly higher in the follicular phase of the oestrous cycle only in the case of the flush cytology $(\mathrm{P}=0.008)$. In the follicular phase, the percentage of TI and TIII cells was statistically significantly higher $(\mathrm{P}<0.001)$ in the smears prepared with a brush than in the smears prepared from lavage, while 
the percentage of other cell types was statistically lower $(\mathrm{P}<0.001)$. In the luteal phase of the oestrus cycle, the percentage of type I and III cells was statistically significantly lower $(\mathrm{P}<0.001$ and $\mathrm{P}=0.031$, respectively $)$ in the smears prepared with a brush than in those from lavage, while the percentage of the remaining cell types was statistically significantly higher - TII and PMNs at $\mathrm{P}<0.001$ and lymphocytes at $\mathrm{P}=0.002$. The progesterone level (Table 2) in the luteal phase was 8 times higher than in the follicular phase of the cycle, and the value was statistically significant $(\mathrm{P}<0.001)$. The 17- $\beta$-estradiol serum level (Table 2) was over 5 times higher in the follicular phase than in the luteal phase, this value was also statistically significant $(\mathrm{P}<0.001)$.

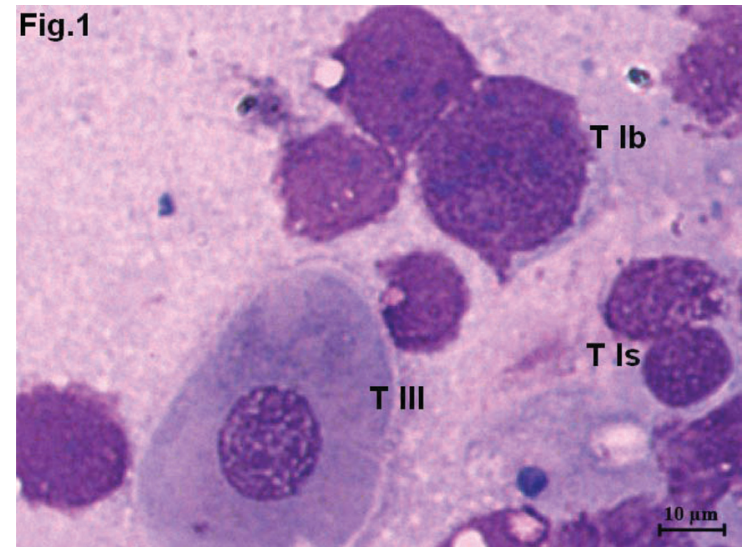

Figure 1. Brush cytology in follicular phase. Cells type I (TI) with atrophic cytoplasm and round small (TIs) and big (TIb) cell nuclei and cells type III (TIII) with clearly visible cytoplasm and small round cell nuclei. Haemacolour staining

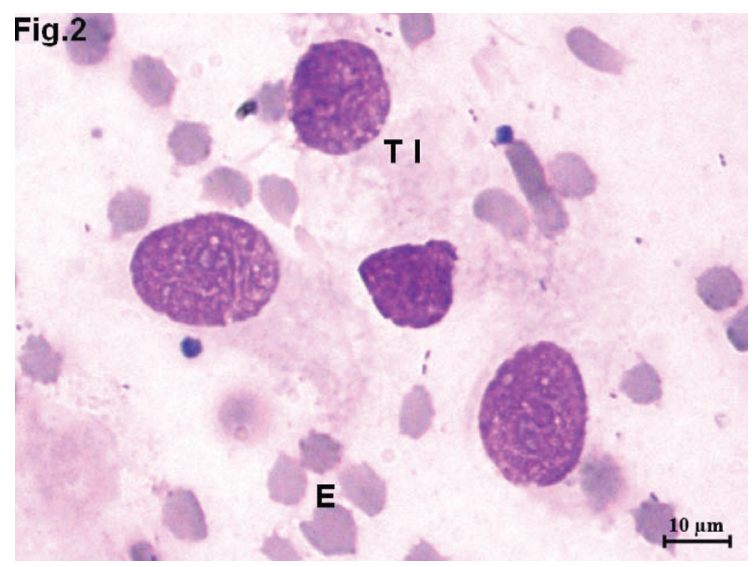

Figure 2. Flush cytology in follicular phase. Cells type I (TI) with atrophic cytoplasm and round cell nuclei and erythrocytes (E). Haemacolour staining 


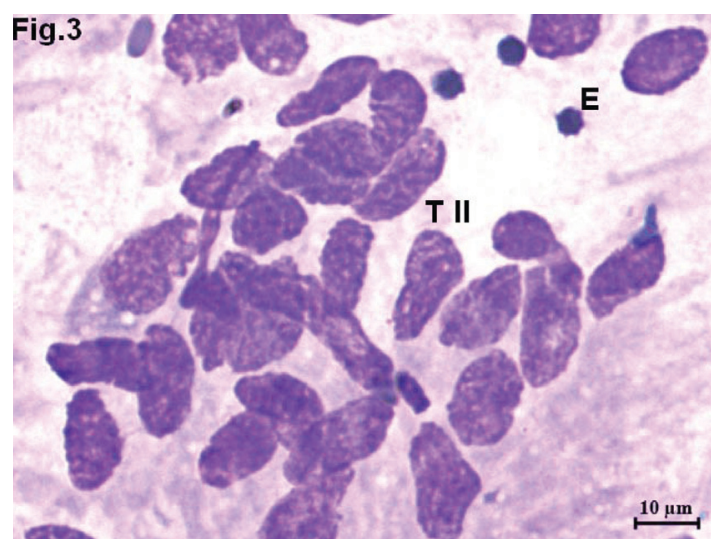

Figure 3. Brush cytology of the uterus in luteal phase. Cells type II (TII) with comma-shaped, conical or cylindrical cell nuclei and erythrocytes (E). Haemacolour staining

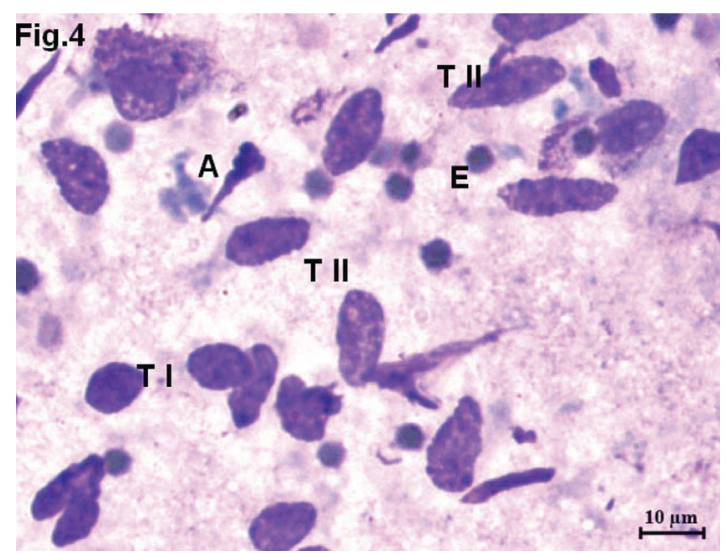

Figure 4. Flush cytology of uterus in luteal phase. Cells type II (TII) with comma-shaped, conical or cylindrical cell nuclei, cells type I (TI), erythrocytes (E) and artefacts (A). Haemacolour staining

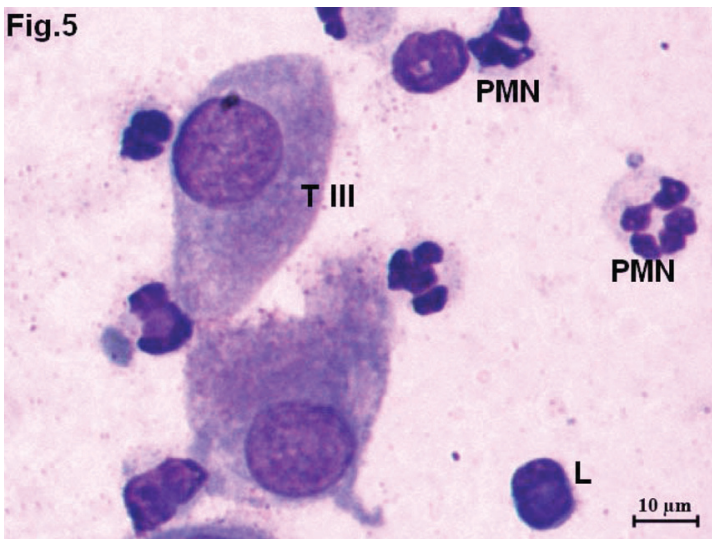

Figure 5. Inflammation of the uterus in follicular phase. Cells type III (TIII) with clearly visible cytoplasm and small round cell nuclei, lymphocytes (L) and neutrophils (PMN). Haemacolour staining 
Table 1. Comparison of the number of cells in the smears collected by brush and uterine flushing $($ mean \pm SEM)

\begin{tabular}{|c|c|c|c|c|c|c|}
\hline \multirow[b]{2}{*}{$\begin{array}{l}\text { Phase of the estrous } \\
\text { cycle } \\
(n=10 \text { in each group) }\end{array}$} & \multicolumn{6}{|c|}{ Type of cells observed in the cytological samples from the uterus } \\
\hline & $\begin{array}{l}\text { type I cells } \\
(\%)\end{array}$ & $\begin{array}{c}\text { type II cells } \\
(\%)\end{array}$ & $\begin{array}{c}\text { type III cells } \\
(\%)\end{array}$ & $\begin{array}{c}\text { polymorpho- } \\
\text { nuclear cells } \\
-\mathrm{PMN}(\%)\end{array}$ & $\begin{array}{c}\text { lymphocytes } \\
(\%)\end{array}$ & $\begin{array}{c}\text { artefacts } \\
\text { small (-) } \\
\text { or large (+) } \\
\text { amount }\end{array}$ \\
\hline (B) follicular phase & $\begin{array}{c}65.1 *, \# \\
\pm 4.72\end{array}$ & $\begin{array}{c}11.6^{*}, \# \\
\pm 2.49\end{array}$ & $\begin{array}{c}19.2 *, \# \\
\pm 2.67\end{array}$ & $\begin{array}{l}2.8 \# \\
\pm 1.72\end{array}$ & $\begin{array}{l}1.3 \# \\
\pm 0.9\end{array}$ & + \\
\hline (B) luteal phase & $\begin{array}{l}14.8 \# \\
\pm 2.04\end{array}$ & $\begin{array}{c}75.43 \# \\
\pm 4.67\end{array}$ & $\begin{aligned} & 7.4 \\
\pm & 2.42\end{aligned}$ & $\begin{array}{c}1.3 \# \\
\pm 1.41\end{array}$ & $\begin{array}{l}1.1 \# \\
\pm 0.7\end{array}$ & - \\
\hline (F) follicular phase & $\begin{array}{l}49.3 * \\
\pm 9.12\end{array}$ & $\begin{array}{l}30.3 * \\
\pm 5.39\end{array}$ & $\begin{array}{c}8.8^{*} \\
\pm 3.12\end{array}$ & $\begin{array}{l}7.4^{*} \\
\pm 3.2\end{array}$ & $\begin{array}{c}4.2 \\
\pm 1.8\end{array}$ & ++ \\
\hline (F) luteal phase & $\begin{array}{c}31.7 \\
\pm 6.34\end{array}$ & $\begin{array}{c}55.5 \\
\pm 9.73\end{array}$ & $\begin{array}{c}5.0 \\
\pm 1.89\end{array}$ & $\begin{array}{c}4.2 \\
\pm 1.72\end{array}$ & $\begin{array}{c}3.6 \\
\pm 2.2\end{array}$ & + \\
\hline
\end{tabular}

(B) - brush cytology.

(F) - flush cytology.

* - statistically significant differences between cows in the follicular phase and cows in the luteal phase for $\mathrm{P}<0.01$.

\#-statistically significant differences between cows in the follicular phase - brush cytology and cows in the follicular phase - flush cytology and between cows in the luteal phase - brush cytology and cows in the luteal phase - flush cytology for $\mathrm{P}<0.01$.

Table 2. Serum levels of progesterone $(\mathrm{ng} / \mathrm{ml})$ and $17-\beta$ estradiol $(\mathrm{pg} / \mathrm{ml})$ in the experimental groups $(\mathrm{n}=20$ in each group) (mean \pm SEM)

\begin{tabular}{l|c|c}
\hline \multirow{2}{*}{ Phase of the oestrous cycle } & \multicolumn{2}{|c}{ Hormone } \\
\cline { 2 - 3 } & progesterone & $17-\beta$ estradiol \\
\hline Cows in the follicular phase & $1.31 \pm 0.83^{*}$ & $19.82 \pm 2.41^{*}$ \\
Cows in the luteal phase & $10.52 \pm 1.82$ & $3.65 \pm 1.33$ \\
\hline
\end{tabular}

* - statistically significant differences between mean values within each column for $\mathrm{P}<0.001$.

\section{Discussion}

Cytological examination is performed in cows mainly in order to rule out or confirm subclinical endometritis (LeBlanc et al., 2002; Sheldon and Dobson, 2004; Kasimanickam et al., 2005; Jeremejeva et al., 2010). This examination is currently decisive in diagnosing subclinical endometritis, and provides the basis for a classification of uterine inflammation by Sheldon (Sheldon et al., 2006, 2009), which is still in use. Above publications do not refer to the state of the uterus without inflammation. The absence of leukocyte infiltration in the uterus does not always mean that the state of the endometrium is normal. The uterus and ovaries are interdependent organs. Cyclically appearing ovarian structures, through their secretion activity and hormone production, have a direct impact on the uterus, particularly the endometrium. The uterus affects the cyclical changes on the ovaries as well, e.g. by producing prostaglandin $\mathrm{PGF}_{2 a}$, which has luteolytic properties (Lucy et al., 2004; Binelli et 
al., 2009; Lamb et al., 2010). Therefore, the cytological image of the endometrium should change depending on the current ovarian structure. This seems to be of considerable importance in veterinary practice for confirming the physiological state of the endometrium, as well as for recognizing the phases of the ovarian cycle. The type of cells currently present in the uterus, and the percentage of different types of epithelial cells are of significance. The results of the study showed distinct differences between the follicular and luteal phases, in the percentages of different types of cells visible in the cytological image of the endometrium. These changes were unquestionably linked to the hormonal activity corresponding to the changing structures on the ovary during the repeated ovarian cycle. The hormonal activity of particular ovarian structures was confirmed in the present study, by determining the concentration of 17- $\beta$-estradiol and progesterone. Hormones indirectly, through their positive or negative effect on the uterine blood supply, influence the proliferation, necrosis, exfoliation or regeneration of the endometrial epithelium (Deligidisch, 2000; Fraser et al., 2008). Estrogens improve the uterine blood supply and, as hormones stimulating cell division, promote proliferation of endometrial cells (Sit et al., 2004; Groothuis et al., 2007; Fraser et al., 2008; Brodzki et al., 2011). This leads to exfoliation and necrosis of existing epithelial cells and the appearance of young cells in the lumen of the uterus. This is confirmed by the present study, particularly as the cytological evaluation was supported by hormone level tests (estradiol and progesterone). The most varied cytological image was observed during the follicular phase, when the concentration of estradiol was high and concentration of progesterone low. A large number of young epithelial cells with distinct cytoplasm and small or large round nuclei (TIII) were observed. Also, exfoliated epithelial cells in various degrees of degeneration were observed (mainly TI, with a small number of TII cells), which also indicates that rapid proliferation was occurring at this time. In cows during the oestrous cycle, oestrogen high concentration acts for only a few days, but the changes occurring in the endometrium during the follicular phase are clearly visible. As the corpus luteum gradually develops following ovulation, producing increasing quantities of progesterone, the proliferation processes in the endometrium gradually come to an end. Progesterone, in contrast with estrogens, decreases the uterine blood supply, which substantially reduces proliferation of the endometrial epithelium (Hussain, 1989; Hansen, 1998; Bartolome et al., 2005). At this time a visible effect in the cytological examination is the low percentage of young epithelial cells (TIII), while the percentage of exfoliated cells of the uterine epithelium is the highest, particularly the type II cells characteristic of this period.

The study also aimed to compare the two most frequently described methods for collecting cytological material from the uterus in cows - a cytological brush (B) and flush (F) (Kasimanickam et al., 2005; Prieto et al., 2012). The changes in the cytological image in each phase of the ovarian cycle were visible in both of the methods evaluated. However, the differences in the proportions of different types of cells were more visible in the smears prepared using cytological brushes than those prepared from lavage. Moreover, smears prepared using the B method contained more epithelial cells and fewer artefacts, which made them much easier to evaluate under a microscope. The differences in the quality of the cytological smears prepared in the 
two methods, result from the depth at which material is collected. When we collect lavage, we obtain almost exclusively cells located on the surface of the endometrium and in the lumen of the uterus, whereas the brush is constructed in a way that allows cells to be collected not only from the surface but also from somewhat deeper layers of the endometrium, ensuring a better and more accurate image of the current state of the uterus. Literature data also show that hormonal activity influences the number of immune cells in the uterine cavity and in the endometrium; more leukocytes are present in the follicular phase than in the luteal phase (Hussain, 1989; Lewis, 2004; Bartolome et al., 2005; Brodzki et al., 2014). In the present study, a statistically significant increase was not noted in the number of leukocytes in the cytological image obtained using B, although the percentage of PMNs during the follicular phase was markedly higher than in the luteal phase. In the flush cytology the differences between the follicular and luteal phases are even more pronounced, and statistically significant. The higher number of PMNs in the flush cytology is due to the fact that the material was collected from a much larger surface of the uterus than in the case of the brushes (Kasimanickam et al., 2005; Prieto et al., 2012).

Identification of different phases of the oestrus cycle in cows poses many problems for both breeders and veterinarians dealing with reproduction. The difficulty is not with normal cycles and symptoms of oestrus, but with the increasingly common problematic cycles in which the signs are very indistinct, atypical, or even absent. The most difficult cases involve cows that have been unsuccessfully inseminated or mated multiple times, veterinarians then attempt to find the cause of infertility. Most of these causes are simple errors such as incorrect identification of oestrus, insemination at the wrong time, or failure to conduct additional basic tests to ascertain the state of the endometrium (Sturman et al., 2000; Stevenson, 2001). The results of the present study constitute model data facilitating identification of phases of the ovarian cycle, so that at least some of these errors in management of reproduction in cows can be avoided. A cytological examination should always be performed when diagnosing infertility of unknown origin in cows, mainly as an additional method to ultrasonography, which does not provide an adequate image of the endometrium. In this situation ultrasonography detects the presence of the structure on the ovary corresponding to a given phase of the ovarian cycle, while cytology is used to ascertain whether the endometrium is exhibiting characteristic changes for this phase; at the same time, we make sure that the uterus is free of inflammation. A biopsy and histopathological examination is more precise, but is also more invasive and takes more time; moreover, it must be performed in a specialized laboratory by someone with experience with this type of examination (Chapwanya et al., 2010; Garoussi et al., 2010). The cytological examination described in this paper can be performed quickly and is relatively less invasive. It can be performed by most veterinarians, of course after appropriate training. It is important that cytological examinations are conducted routinely, as this will enable precise observation of the differences between the normal state of the endometrium and pathological changes. In clinical practice while dealing with reproduction in cattle, confirmation of the normal state of the uterus is the foundation for the diagnostic of other causes of infertility, and reduces time and economic losses, associated with unnecessary treatment of suspected endometritis. 
The results of the study show that phases of the ovarian cycle in cows can be identified based on changes in the quality and percentage of different types of endometrial cells in a cytological examination. The results of this study constitute model data, as there is no available literature directly related to this question. The usefulness of this method for veterinarians overlooking reproduction in cow herds confirms the fact that the examination described can be performed quickly and is relatively non-invasive, especially when a cytological brush is used, and provides useful information concerning the state of the endometrium and the current phase of the ovarian cycle. This method helps mainly when searching for the causes of infertility and difficulties in assessing the ovarian cycle phases.

\section{References}

Bartolome J.A., Silvestre F.T., Kamimura S., Arteche A.C.M., Melendez P., Kelbert D., M c Hale J., Swift K., A r chbald L.F., Thatcher W.W. (2005). Resynchronization of ovulation and timed insemination in lactating dairy cows: I: use of the Ovsynch and Heatsynch protocols after non-pregnancy diagnosis by ultrasonography. Theriogenology, 63: 1617-1627.

B in elli M., M a ch ad o R., B erg a m a s ch i M.A.C.M., B ert a n C.M. (2009). Manipulation of ovarian and uterine function to increase conception rates in cattle. Anim. Reprod., 6: 125-134.

B is inotto R.S., Greco L.F., Ribe iro E.S., Martinez N., Lima F.S., Staples C.R., Thatch er W.W., S a n to s J.E.P. (2012). Influences of nutrition and metabolism on fertility of dairy cows. Anim. Reprod., 9: 260-272.

Brodzki P., Wrona Z., Piech T., Brodzki A. (2011). Effect of cytostatics on the selected parameters of cell-mediated immunity in dogs. Bull. Vet. Inst. Pulawy, 55: 87-93.

Brodzki P., Brodzki A., Kostro K., Kurek L., Marczuk J., Krakowski L. (2014) Cytology of the endometrium in cows being in follicular and luteal phases of the ovarian cycle and in cows with follicular and luteal ovarian cysts. Bull. Vet. Inst. Pulawy, 58: 141-147.

$\mathrm{C}$ h a p w an y a A., M e a d e K.G., N a r c i and i F., S t a n le y P., M e J.F., D o he r ty M.L., C a lla n a n J.J., F arrel1y C.O. (2010). Endometrial biopsy: a valuable clinical and research tool in bovine reproduction. Theriogenology, 73: 988-994.

D e li g d is c h L. (2000). Hormonal pathology of the endometrium. Mod. Pathol., 13: 285-294

Fraser H.M., Wils on H., Silvestri A., Morris K.D., Wi egant S.J. (2008). The role of vascular endothelial growth factor and estradiol in the regulation of endometrial angiogenesis and cell proliferation in the marmoset. Endocrinology, 149: 4413-4420.

Garoussi M.T., S a sani F., Hovareshti P. (2010). The histopathological survey of tissue in Holstein dairy cows with or without recorded reproductive disorders. Ir. J. Vet. Sci. Technol., 2: $101-108$.

Groo thu is P.G., Das se n H.H., R om an o A., Punyade er a C. (2007). Estrogen and the endometrium: lessons learned from gene expression profiling in rodents and human. Hum. Reprod. Update, 13: 405-417.

$\mathrm{H}$ a $\mathrm{n}$ s e n P.J. (1998). Regulation of uterine immune function by progesterone - Lessons from the sheep. J. Reprod. Immunol., 40: 63-70.

Hu s s a in A.M. (1989). Bovine uterine defense mechanisms: A review. J. Vet. Med. Series B, 36: $641-651$.

Jere m ejev a J., Orro T., Valdman n M., K a sk K. (2010). Bacteriological and cytological findings during the late puerperal period after two different treatments of retained placenta followed by acute puerperal metritis. Acta Vet. Scand., 52: p. 41.

Kas imanickam R., Duffield T.F., Foster R.A., Gartley C.J., Le slie K.E., Walto n J.S., J o h n s o n W.H. (2004). Endometrial cytology and ultrasonography for the detection of subclinical endometritis in postpartum dairy cows. Theriogenology, 62: 9-23.

Kas imanickam R., Duffield T.F., Foster R.A., Gartley C.J., Le slie K.E., Walt - 
on J.S., J o h n s o n W.H. (2005). A comparison of the cytobrush and uterine lavage techniques to evaluate endometrial cytology in clinically normal postpartum dairy cows. Can. Vet. J., 46: 255259.

L a mb G.C., D ah le n C.R., L ars on J.E., M a rque zini G., S t e ven s on J.S. (2010). Control of the oestrous cycle to improve fertility for fixed-time artificial insemination in beef cattle: a review. J. Anim. Sci., 88: 181-192.

LeBlanc S.J., Duffield T.F., Le s li e K.E., B at e man K.G., Ke efe G.P., Walton J.S., J o h n s on W.H. (2002). Defining and diagnosing postpartum clinical endometritis and its impact on reproductive performance in dairy cows. J. Dairy. Sci., 85: 2223-2236.

L e B 1 a n c S.J. (2012). Interactions of metabolism, inflammation, and reproductive tract health in the postpartum period in dairy cattle. Reprod. Dom. Anim., 47: 18-30.

L ew is G.S. (2004). Steroidal regulation of uterine immune defences. Anim. Reprod. Sci., 82: 281-294.

L u c y M.C., M c D o u ga 11 S., N a t i o n D.P. (2004). The use of hormonal treatments to improve the reproductive performance of lactating dairy cows in feedlot or pasture-based management systems. Anim. Reprod. Sci., 82: 495-512.

Melcher Y., Prunner I., Drilli ch M. (2014). Degree of variation and reproducibility of different methods for the diagnosis of subclinical endometritis. Theriogenology, 82: 57-63.

Prieto M., Barrio M., Quintela L.A., Perez-Martin C.C., B ecerra J.J., Vigo M., Diaz C., Cainzos J., Prieto A., Fernandez F.I., Martinez D., Herradon P.G. (2012). Validation of simple method for the interpretation of uterine cytology in cows. Vet. Med., 57: 360-363.

Sheldon I.M., D obs on H. (2004). Postpartum uterine health in cattle. Anim. Reprod. Sci., 82: 295-306.

Sheldon I.M., Levis G.S., L e B lan c S., Gilbert R.O. (2006). Defining postpartum uterine disease in cattle. Theriogenology, 65: 1516-1530.

Sheldon M., Cron in J., Goetze L., Don ofrio G., S chuberth H.J. (2009). Defining postpartum uterine disease and the mechanisms of infection and immunity in the female reproductive tract in cattle. Biol. Reprod., 81: 1026-1032.

S it A.S.Y., Modugno F., Hill L.M., Martin J., We is s feld J.L. (2004). Transvaginal ultrasound measurement of endometrial thickness as a biomarker for estrogen exposure. Cancer. Epidemiol. Biomarkers Prev., 13: 145-149.

Stevens on J.S. (2001). Reproductive management of dairy cows in high milk-producing herds. J. Dairy Sci., 84: 128-143.

Sturman H., Olte nacu E.A.B., F o ote R.H. (2000). Importance of inseminating only cows in estrus. Theriogenology, 53: 1657-1667.

Turner M.L., Healey G.D., Sheld on I.M. (2012). Immunity and inflammation in the uterus. Reprod. Dom. Anim., 47: 402-409.

W a th e s D.C. (2012). Mechanisms linking metabolic status and disease with reproductive outcome in the dairy cow. Reprod. Dom. Anim., 47: 304-312.

Received: 13 VII 2014

Accepted: 3 XI 2014 